Original Article

\title{
Barriers to the Access of Oral Health Care in Individuals from Lower Socioeconomic Communities in Karachi
}

\author{
Afifa Hemani, Faiza Rauf, Muhammad Yahya Noori, Asima Faisal
}

\section{ABSTRACT}

INTRODUCTION: Oral healthcare is a broad term that includes well-being of teeth, gums and broader oral environment. It is considered as a window to personal, economic and social development of individuals, irrespective of their age and gender. Poor oral health may lead to depression, demoralization, stress, and low self-esteem and may even impact social relations of an individual while also leading to great financial costs. It has direct impact on the physical health of an individual and it can be associated with chronic conditions including stroke, heart disease, diabetes, and cancer. The direct and indirect cost of poor oral health is very high as millions of school days and working hours are lost each year primarily because issues related to oral hygiene. It is unfortunate that oral treatment is considered amongst the most expensive treatments around the world, which hinders access of low and middle socioeconomic classes to proper oral health care mainly due to financial costs associated with it.

OBJECTIVE: To determine the barriers that hinders the access to oral healthcare service utilization of low socio-economic communities in Karachi.

METHODOLOGY: This cross sectional survey, after ethical approval from the Health Management Department of the College of Business Management, was carried out from March to June 2015. Using OpenEpi online calculator, sample size calculated and 385 respondents were randomly selected from two distinct low socio-economic communities of the Karachi. Data collected using World Health Organization Oral Health Survey Questionnaire for assesing personal and environmental factors influencing access to oral health service and analyzed using SPSS ${ }^{\circledR}$ version 22.

RESULTS: Most of the participants were young-middle aged having some form of formal education. More than half of the participants had no access to a regular personal dentist before. About two-thirds deferred dental treatment as it was a considerable financial burden on their budget. We found statistically significant association between access to a regular dentist and educational qualification $(p=0.000)$ and perceived expense of dental treatment $(p=0004)$, while it was insignificant $(p=0.48)$ between access to a regular dentist and time taken for travelling.

CONCLUSION: For those from low socioeconomic communities, education and travelling plays a role in limiting access to dental health care, however most powerful deterrent for such individuals is financial constraint.

KEY WORDS: Access to Oral Health, Personal Barriers, Financial Costs, Environmental Barriers.

This article may be cited as: Hemani A, Rauf F, Noori MY, Faisal A. Barriers to the Access of Oral Health Care in Individuals from Lower Socioeconomic Communities in Karachi. J Liaquat Uni Med Health Sci. 2017;16(04):218-21. doi: 10.22442/jlumhs.171640537

\section{INTRODUCTION}

Oral healthcare is a broad term that includes wellbeing of teeth, gums and broader oral environment. It is considered as a window to personal, economic and social development of individuals, irrespective of their age and gender ${ }^{1}$. Poor oral health may lead to depression, demoralization, stress, and low self-esteem and may even impact social relations of an individual while also leading to great financial costs $^{2}$. It has direct impact on the physical health of an individual and it can be associated with chronic conditions including stroke, heart disease, diabetes, and cancer ${ }^{3-5}$. The direct and indirect cost of poor oral health is very high as millions of school days and working hours are lost each year primarily because issues related to oral hygiene ${ }^{6}$. It is unfortunate that oral treatment is considered amongst the most expensive treatments around the world, which hinders access of low and middle socioeconomic classes to proper oral health care mainly due to financial costs associated with it. In Pakistan, Oral health issues are generally neglected, until there is a dire need to attend the dentist. Though there has been some effort in increasing the supply of the oral health practitioners, there is still dire need for developing properly institutionalized oral health system, so that people can easily access oral health services ${ }^{7-9}$.

Since not attending a regular dentist, missing dental 
appointments, or ignoring dental health, increases the magnitude and cost of the problem and leads to additional preventable suffering, it is important to study the barriers faced by different populations so that actions can be taken to increase patient attendance and compliance for regular dental checkups. The current study was carried out to assess the major barriers, which prevent access to oral health care in the low socio-economic communities in Karachi.

Objective: To determine the barriers that hinders the access to oral healthcare service utilization of low socio-economic communities in Karachi.

\section{METHODOLOGY}

After Ethical approval from the Health Management Department of Institute of Business Management this cross-sectional questionnaire based study was carried out between March-June 2015. A sample size of 385, with $95 \%$ confidence interval and $5 \%$ margin of error was calculated using OpenEpi. Sampling population was selected includes two distinct low socioeconomic areas adjacent to the Gulshan and Saddar town of Karachi. Participants aged 18 years or more, after taking informed written consent, were recruited by simple random sampling as per the random number generated online ${ }^{10}$.

WHO-Oral Health Survey ${ }^{11}$ used as tool to collect relevant information. This questionnaire consists of three parts, first part is for collecting demographical information, second part identifies personal barriers and third for environmental barriers that prevents access to oral health service. Statistical analysis was performed using SPSS Version 22.

\section{RESULTS}

The response rate remained $96 \%$. Male and female

participants were equally distributed. According to age, $30.1 \%$ of the total participants were aged between $26-35$ years, $21 \%$ were $36-45$ years old, $15.1 \%$ were $46-55$ years old, $7 \% 56-65$ years old, and $11.9 \%$ of the participants were older than 65 years of age. Among the participants $84 \%$ had some form of education, while $16.6 \%$ of the participants had no formal education. When inquired about prior consultation for dental treatment, only $46 \%$ of the total population had consulted dentists for oral care; $53.8 \%$ of the participants indicated that they didn't have any personal dentist to care for them as the dental treatment is quite expensive in relation to their monthly income. In particular, $70.9 \%$ of the participants indicated that dental treatment has significantly affected their monthly budget because of the expenses associated with dental care. There was considerable travel time involved in reaching to the dental facility, and majority of the patients have to travel for one to two hours to get to the dental facility. As shown in table 2, there is a statistically significant association $(p=0.000)$ between educational qualification and having a regular personal dentist. The perceived expense of dental treatment and access to a regular dentist also showed significant association $(p=0.04)$, however association between access to regular dentist and the time taken for travelling was statistically insignificant as shown in table no 3.

TABLE I: TIME TAKEN TO TRAVEL TO A DENTAL FACILITY

\begin{tabular}{|l|c|c|}
\hline Time to Travel (Hours) & Frequency (n) & Percent \\
\hline Less than One Hour & 93 & 24.2 \\
\hline One to Two Hours & 277 & 71.5 \\
\hline More than Two Hours & 15 & 3.9 \\
\hline
\end{tabular}

TABLE II: ASSOCIATION OF EDUCATION WITH REGULAR ACCESS TO A DENTIST

\begin{tabular}{|l|c|c|c|c|c|c|}
\hline \multicolumn{1}{|c|}{ Education Level } & $\begin{array}{c}\text { With Regular } \\
\text { Access to Dentist }\end{array}$ & $\begin{array}{c}\text { Without Regular } \\
\text { access to Dentist }\end{array}$ & Total & $\mathbf{X}^{\mathbf{2}}$ & $\boldsymbol{d f}$ & $\boldsymbol{P}$ \\
\hline No formal education & 16 & 47 & 63 & - & - & - \\
\hline Primary & 13 & 21 & 34 & - & - & - \\
\hline Secondary & 12 & 34 & 46 & 32.45 & 4 & 0.000 \\
\hline High school & 28 & 38 & 66 & - & - & - \\
\hline College/University/Postgraduate & 87 & 55 & 142 & - & - & - \\
\hline Total & $\mathbf{1 5 6}$ & $\mathbf{1 9 5}$ & $\mathbf{3 5 1}$ & - & - & - \\
\hline
\end{tabular}

TABLE III: ASSOCIATION OF COST PERCEPTION WITH REGULAR ACCESS TO A DENTIST

\begin{tabular}{|l|c|c|c|c|c|c|}
\hline Perception of Dental Treatment & Access to Dentist & No Access to Dentist & Total & $\mathbf{X}^{\mathbf{2}}$ & $\boldsymbol{d f}$ & $\boldsymbol{p}$ \\
\hline Expensive & 161 & 165 & 326 & 8.51 & 1 & 0.004 \\
\hline Not Expensive & 17 & 42 & 59 & - & - & - \\
\hline Total & $\mathbf{1 7 8}$ & $\mathbf{2 0 7}$ & $\mathbf{3 8 5}$ & - & - & - \\
\hline
\end{tabular}




\section{DISCUSSION}

The results of this study showed that the cost of dental treatment is significantly associated with the access to a personal dentist. Although the current study was conducted on lower socioeconomic population, yet the participants were still predominantly urban (96\%) and majority of the participants were between the ages of 26 years to 45 years. Unfortunately, oral health disparities are globally common and treatment cost remains the major barrier to the access of oral healthcare world-wide. These results are in agreement with other studies from the developing as well as developed countries where cost is the major factor that leads to delays in seeking oral health, especially for the marginalized communities such as migrants, refugees and people with disabilities ${ }^{13-16}$.

Other important factor associated with the lack of regular access to a dentist was patients' educational level. Since low-socioeconomic class generally has limited access to the educational and health facilities ${ }^{17}$, and mostly the quality of whatever available is also compromised, this is an anticipated phenomenon and lack of awareness about health issues in general, as well as decreased health literacy in the local population ${ }^{18}$ complicate the problem further.

We also observed that considerable time was involved in traveling to the dental care facility and this would certainly add to the barriers involved in access to the dental health facility, though statistical testing did not show that travel time is associated with lack of access to a personal dentist.

Our study was focused only on the lower socioeconomic class in two particular areas, so the findings may not be generalized to entire city and all of the population, which can be considered the limitation of our study. The issues may vary in different areas and different socio-economic classes.

\section{CONCLUSIONS AND RECOMMENDATIONS}

Our study found different barriers affecting access to oral healthcare, which signifies that systematic and coordinated efforts should be made to decrease the cost and travel time to the dental health facilities by providing Primary Healthcare Centers to the deprived communities of the cities, where they can have access to regular dentists in their vicinity. Special efforts should be made to decrease the cost of dental services. These centers could also be used to increase patient literacy and healthcare awareness in these communities. This would help in decreasing the burden of disease and shift our focus from treatment to prevention. Moreover, awareness programs should be developed to introduce oral health to the population so that utilization can be improved.

\section{REFERENCES}

1. Donoff $B$, McDonough JE, Riedy CA. Integrating oral and general health care. New Engl J Med. 2014; 371: 2247-2249. DOI: 10.1056 NEJMp 1410824

2. Petersen PE. The World Oral Health Report 2003: Continuous improvement of oral health in the 21st century, the approach of the WHO Global Oral Health Programme. Community Dent Oral epidemiol. 2003; 31(s1):3-24.

3. Hajishengallis G. Periodontitis: From microbial immune subversion to systemic inflammation. Nat Rev Immunol. 2015; 15(1):30-44. doi: 10.1038/ nri3785.

4. Noble JM, Scarmeas N, Papapanou PN. Poor oral health as a chronic, potentially modifiable dementia risk factor: Review of the literature. Curr Neurol Neurosci Rep. 2013; 13(10):384. doi: 10.1007/ s11910-013-0384-x.

5. Yao QW, Zhou DS, Peng HJ, Ji P, Liu DS. Association of periodontal disease with oral cancer: A meta-analysis. Tumor Biol. 2014; 35(7):7073-7. doi: 10.1007/s13277-014-1951-8.

6. Jin LJ, Lamster IB, Greenspan JS, Pitts NB, Scully C, Warnakulasuriya S. Global burden of oral diseases: emerging concepts, management and interplay with systemic health. Oral Dis. 2016;22(7):609-19. doi: 10.1111/odi.12428.

7. Basharat S, Shaikh BT. Primary oral health care: A missing link in public health in Pakistan. EMHJ. 2016; 22(9):703-6.

8. Khan AA. Dentistry in Pakistan-Standing at the Crossroads Facing Numerous Challenges with an Uncertain Future. JPDA. 2015; 25(1):1-2.

9. Mubeen N, Nisar N. Pattern of dental health care utilizations among mothers in Karachi, Pakistan. International Journal of Dental Clinics. 2015;7 (3): 10-13.

10. Services Ral. Random.org. Dublin: Randomness and Integrity Services; [cited 2015]; Available from: https://www.random.org/.

11. Petersen PE, Baez RJ. Oral health surveys basic methods. $5^{\text {th }}$ edn. Geneve, World Health Organization:2013; 84-92.

12. IBM. IBM SPSS for Windows. 22 ed. New York: IBM Corp; 2013.

13. Kandelman D, Arpin S, Baez RJ, Baehni PC, Petersen PE. Oral health care systems in developing and developed countries. Periodontol 2000. 2012; 60(1):98-109. doi: 10.1111/j.16000757.2011.00427.x

14. Flores $\mathrm{G}$, Lin $\mathrm{H}$. Trends in racial/ethnic disparities in medical and oral health, access to care, and use of services in US children: Has anything changed over the years? Int J Equity Health. 
2013; 12(1):10. doi: 10.1186/1475-9276-12-10

15. Keboa MT, Hiles N, Macdonald ME. The oral health of refugees and asylum seekers: A scoping review. Global Health. 2016;12(1):59-60.

16. Naseem M, Shah AH, Khiyani MF, Khurshid Z, Zafar MS, Gulzar S, et al. Access to oral health care services among adults with learning disabilities: A scoping review. Ann Stomatol (Roma). 2016;7(3):52-9. doi: 10.11138/ ads/2016.7.3.052
17. Kumar R, Joshi D. Awareness of dental hygiene amongst the primary school children of low socio-economic strata. Int J Contemp Pediatrics. 2017;4(1):28-35.

18. Noori MY, Kazi M, Shahid A, Faisal A. The Relationship of Health Literacy, Perceived Health Information Need and Preventive Health Related Behavior in Urban Karachi. J Islamic Int Med Coll. 2015;10(3):210-3.

\begin{tabular}{|l|}
\hline AUTHOR AFFILIATION: \\
Afifa Hemani \\
Health and Hospital Management \\
Institute of Business Management \\
Karachi, Sindh-Pakistan. \\
Faiza Rauf \\
Faculty of Pharmacy \\
University of Karachi \\
Karachi, Sindh-Pakistan. \\
Dr. Muhammad Yahya Noori \\
(Corresponding Author) \\
Assistant Professor of Pathology \\
Dow International Medical College \\
Dow University of Health Sciences \\
Karachi, Sindh-Pakistan. \\
Email: yahyanoori@gmail.com \\
Asima Faisal \\
Head, Department of Health Management \\
College of Business Management \\
Institute of Business Management \\
Karachi, Sindh-Pakistan. \\
\hline
\end{tabular}

